\title{
Time of onset of iridocyclitis (IC) in children with juvenile idiopathic arthritis (JIA)
}

\author{
S Verazza*1, M Allegra ${ }^{1}$, B Lattanzi ${ }^{1}$, S Dalprà ${ }^{1}$, S Magni-Manzoni ${ }^{5}$, \\ A Pistorio ${ }^{1}$, S Oliveira ${ }^{2}$, E Castell ${ }^{3}$, O Arguedas ${ }^{4}$, A Martini ${ }^{1}$ and A Ravelli ${ }^{1}$
}

\begin{abstract}
Address: ${ }^{1}$ IRCCS G. Gaslini, Genoa, Italy, ${ }^{2}$ Universidade Federal do Rio de Janeiro, Rio de Janeiro, Brazil, ${ }^{3}$ Hospital General de Ninos P. Elizalde, Buenos Aires, Argentina, ${ }^{4}$ Hospital Nacional de Ninos Herrera, San José, Costa Rica and ${ }^{5}$ IRCSS Pol. San Matteo, Pavia, Italy

* Corresponding author
\end{abstract}

from I5th Paediatric Rheumatology European Society (PreS) Congress

London, UK. 14-17 September 2008

Published: 15 September 2008

Pediatric Rheumatology 2008, 6(Suppl I):P77 doi:I0.1 I86/I546-0096-6-SI-P77

This abstract is available from: http://www.ped-rheum.com/content/6/SI/P77

(c) 2008 Verazza et al; licensee BioMed Central Ltd.

\section{Background}

IC is one of the most important extra-articular complications of JIA. However, little information exists on the time of onset of IC during the disease course.

\section{Objective}

To evaluate the frequency of IC onset over time in JIA patients who developed this complication.

\section{Methods}

1050 JIA patients seen between 1985 and 2007 were identified. 172 patients (16.4\%) had IC. 6 patients with enthesitis-related arthritis with acute IC, 4 patients who developed IC before arthritis onset and 2 patients in whom date of IC onset was unknown were excluded. Of the remaining 160 patients, 108 (67.5\%) had oligoarthritis, $36(22.5 \%)$ RF-negative polyarthritis, 9 (5.6\%) undifferentiated arthritis, $6(3.8 \%)$ psoriatic arthritis, $1(0.6 \%)$ systemic arthritis. Of the 158 patients who had ANA tested, $144(91.1 \%)$ were positive $(\geq 1: 160), 8(5.1 \%)$ low-positive $(\leq 1: 80)$ or doubtful, $6(3.8 \%)$ negative.

\section{Results}

The cumulative proportion of patients who developed IC over time is shown in figure 1 and table 1.

\section{Conclusion}

Of 160 patients who had IC, half developed this complication in the first year, 2/3 in the first 2 years, $4 / 5$ in the first 3 years, and only $5.6 \%$ after 7 years. This suggests that risk of IC onset is greatest in the first 3 years of disease and that the optimal time for reducing the frequency of ophthalmologic visits is 7 years after onset.

Table I:

\begin{tabular}{llllllllll}
\hline Time (years) & $0-1$ & $1-2$ & $2-3$ & $3-4$ & $4-5$ & $5-6$ & $6-7$ & $7-8$ & $8-14$ \\
\hline Cumulative\% & 48.1 & 68.1 & 78.7 & 84.3 & 87.5 & 91.9 & 94.4 & 96.9 & 100 \\
\hline
\end{tabular}




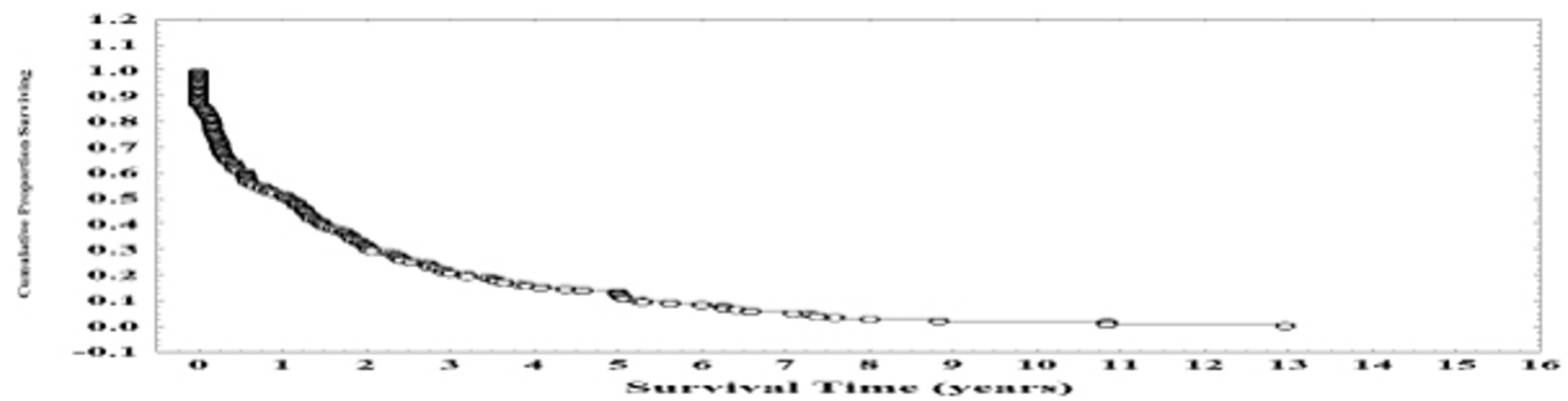

Figure I

Publish with Bio Med Central and every scientist can read your work free of charge

"BioMed Central will be the most significant development for disseminating the results of biomedical research in our lifetime."

Sir Paul Nurse, Cancer Research UK

Your research papers will be:

- available free of charge to the entire biomedical community

- peer reviewed and published immediately upon acceptance

- cited in PubMed and archived on PubMed Central

- yours - you keep the copyright 